Luis Durand

\title{
ALGO SOBRE EL GUENTO Y LOS CUENTISTAS CHILENOS
}

CASI todas las opiniones autorizadas en la materia están de acuerdo en aceptar que el cuento, es el género literario más difícil de explotar con éxito. Dada su corta extensión, aquel que lo cultive, debe poseer condiciones especiales de síntesis, de equilibrio, y a la vez de la ponderación suficiente, capaz de infundirle ese soplo de vitalidad y fuerza espiritual sin la cual ninguna creación artística puede ser lograda. De lo contrario, corre el peligro, de que en lugar de un cuento, apenas consiga obtener un cuadro, o se desborde en una crónica en donde se desperdicien los elementos temáticos que el autor eligió para escribir su obra.

No obstante, pese a estas consideraciones, es éste el género que más ha prosperado en Chile, en tal forma que nuestra literatura cuenta sólo por excepción, con novelistas que, como Blest Gana sean capaces de llevar a efecto, obras de tanto aliento, sin que después ninguno haya alcanzado la magnitud de él. ¿Quiere decir esto que en nuestro país no haya escritores que puedan abordar con éxito la novelas? ¿Que falta la fibra humana y el ambiente, con el relieve y el interés necesario, para juntar el material que le es preciso para lograr su alcanzamiento? Si afirmáramos esto último, la nutrida obra del propio autor citado, nos 
daría el más rotundo de los desmentidos. En cuanto a lo primero creemos que no es posible tomarlo como causa ni siquiera aparente y momentánea.

Lo que hay de verdad, como decía alguien, hace poco con mucho acierto, es que a nuestra literatura le falta aire. Aire que le permita respirar y fortalecerse, para alcanzar un florecimiento verdadero, y se manifieste en toda su amplitud. El escritor vive aquí, asfixiado por un medio que le es hostil, sintiendo gravitar sobre él, innumerables dificultades que le impiden consagrarse por entero a su arte. En esta situación, lo cultiva, puede decirse en calidad de aficionado, puesto que debe trabajar en actividades ajenas a él, para procurarse su propio sustento y el de su familia. En estas condiciones, sólo puede dedicar una parte mínima de su tiempo a perfeccionar las dotes que posee, y esto seguramente, no en las mejores disposiciones intelectuales, pues la más vigorosa parte de su esfuerzo la ha entregado a su labor diaria, de tal manera que sólo le da a su arte, aquellas horas libres, que los demás destinan para ir al cine, meterse en un bar a jugar un cacho, pasear, o sencillamente no hacer nada.

Sobre este respecto, nos asalta esta pregunta: ¿tiene aquí, el escritor, un verdadero aliciente que lo impulse a perseverar en sus tareas? ¿Tiene siquiera, una expectativa de porvenir tranquilo, que lo ponga a cubierto de esas horas inciertas que le sobrevendrán cuando su vitalidad comience a decaer? Triste es declarar que no. El hombre que entrega todo el tesoro de su intimidad o para mejor decir lo único que posee, creando la literatura de su país, no obtiene aquí ninguna retribución que valga la pena. La Humanidad necesita de la belleza, así como cada hombre, individualmente, del amor para poder vivir. Y la expresión de la belleza es el más claro e ideal sentido de la existencia humana, puesto que en sus diversas manifestaciones forma la parte más importante de la cultura, de la cual todo pueblo civili- 
zado vive orgulloso. Entonces, ¿no es justo, de toda justicia, proteger al hombre que la crea?

Sin embargo, aquí en Chile, no hay aún una conciencia clara de estas cosas. En la actualidad no hay ninguna publicación, ya sea revista o diario, que acoja y remunerela colaboración literaria, con excepción de "Atenea". Posiblemente efectos de la crisis, que elimina de la actividad nacional aquello que no cree de absoluta necesidad. Tampoco existen premios que of rezcan alguna posibilidad pecuniaria, de parte de ninguna institución, salvo la muy honrosa de la Universidad de Concepción que, dentro de sus recursos, hace prodigios en pro de la cultura nacional. Y en el público, no hay resonancia, comprensión ni simpatía para el libro chileno, por razones que son largas de explicar y que nos alejarían del tema de este pequeño trabajo. Ante expectativas tan poco amables, ¿se puede esperar que el escritor chileno rodeado de las dificultades señaladas, dedique su escaso tiempo, a escribir novelas cuya consecución, le demandará tranquilidad, estudio, y por lo menos los medios y facilidades del caso, para viajar y conocer siquiera su país?

La novela, pues, a nuestro juicio, si no prospera entre nosotros, no es por falta de capacidad intelectual, sino de tiempo o de profesionalismo literario, en buenas cuentas. Los que la han realizado, podemos observarlo sin gran esfuerzo, son aquellos escritores que disfrutan de independencia económica, o de empleos descansados, que no requieren demasiado esfuerzo intelectual.

Además, es necesario no olvidar que, en general el escritor, una vez concebido el asunto, siente esa tremenda inquietud que es el deseo de ver concluída su obra. Dentro de la situación que comentamos, el cuento ofrece esta posibilidad, a corto plazo y de ahí el auge que ha adquirido en Chile. $Y$ no obstante las condi- 
ciones que necesita para su desarrollo, florece, y da cada día mejores y más sazonados frutos.

De paso, es curioso observar, como todos, o la gran mayoría de los escritores residen en Santiago, circunstancia que hizo decir a uno que comenzaba, que aquí existía una Bastilla literaria, o sea una especie de organismo, para impedir la incorporación a esta pequeña república de las letras, del escritor provinciano. No creemos que esa afirmación pase de ser una sospecha. La obra de calidad se impone sola, pese a todos los obstáculos que se le opongan. Lo que hay de cierto, es que el ambiente literario, estrechado seguramente por las limitaciones anotadas, es mezquino. El escritor se queja de la falta de simpatía que casi siempre rodea a una obra recién aparecida, a veces ante un silencio aplastante. Sin embargo, nada se hace por impedir que este mal cunda, pues cuando el afectado ve repetirse el caso en un compañero, permanece indiferente y quien sabe si hasta en el fondo, siente una satisfacción íntima en que así ocurra. Por cierto que no es el bombo mutuo el que propiciamos, al decir esto, sino el limpio y humano deseo de que el esfuerzo de ca da individuo, llevado a efecto con tantos sacrificios tenga alguna resonancia, forme ambiente y conceptúe al escritor en general, cuando tiene verdadera pasta de tal. Es preciso considerar que estamos en plena forja, y que si el fuelle de esta fragua espiritual sigue soplando siempre malas intenciones, todo resultará destemplado y quebradizo retardando el advenimiento de la creación literaria, que tenga la nobleza del oro puro y alcance la expresión magnífica de lo mejor de nuestro espíritu.

Chile es un país, en donde hay una diversidad de climas bien notoria, que imprimen una característica muy marcada a cada región. Tenemos como es sabido 
desde el clima casi tropical, hasta el polar. Desiertos y valles fertilísimos en el norte. Tierras de migajón, profundas y ricas, en el centro. Tierras pobres, como las del Maule, que ponen a prueba el esfuerzo de sus pobladores. Montañas por cuyos desfiladeros y encrucijadas, arrean en la primavera los baqueanos sus arreos; la región de los lagos con sus panoramas de maravilla y ensueño. Selvas vírgenes donde aun la pupila fosforescente de los pumas asecha a los ternerillos cuando bajan a beber en los esteros que cantan bajo el misterio fresco y enmarañado de los quilantares. Chiloé, donde cada hombre en lugar de un caballo, tiene amarrado un bote cerca de su casa; Magallanes con sus auroras boreales sus pampas inmensas, y sus trágicas soledades. Un litoral dilatadísimo donde viven hombres audaces y aventureros que efectúan hazañas increíbles. En todo esto hay un sello inconfundible y distinto; costumbres, expresiones, leyendas, supersticiones, constituye lo típico, y en cada rincón, nos espera una novedad rica en matices que ofrece motivos hermosísimos, a la inquieta curiosidad del artista.

Sin embargo, la geografía literaria chilena, si así, pudiera llamarse, es limitadísima. Apenas si alcanza a abarcar, malamente, la región comprendida entre las provincias de Santiago y Valdivia. Recién comienza a agrandarse con la producción de Guillermo Koenenkampf que describe en sus cuentos la región de la costa de los campos de Aconcagua, y la de Ernesto Montenegro que crea su "Tío Ventura» curioso e interesante personaje de los alrededores de San Felipe, a través de cuyos labios oímos los relatos que cautivaron nuestra atención en la niñez. Lo demás del norte, apenas si ha sido tocado por el escritor. De Atacama con sus minas fabulosas casi no sabemos nada. La pampa salitrera, con una vida intensa y sus tragedias enormes permanece desconocida para nosotros. Igualmente la isla de Chiloé, cuyas costumbres ofrecen singular relieve y ca- 
racterísticas muy interesantes. De ella conocemos algo de su lexicografía en el lenguaje popular, por los libros del presbítero don Francisco Cavada, y algunos relatos de Humberto Bórquez Solar, en los cuales apenas desflora los motivos que ofrece la vida y costumbres del isleño. Con mayor razón podemos decir esto mismo de Magallanes que, salvo el "Pontón N. ${ }^{\circ} 5$ » de Mariano Latorre, es una tierra completamente extranjera, dentro de nuestra literatura.

¿Qué revela esto? En primer lugar, naturalmente, una falta de interés de los escritores que de allí provienen, por hablar de su tierra y darla a conocer. Pero principalmente se debe, a nuestro juicio, como ya dijimos, a que el escritor permanece encadenado a sus obligaciones y necesidades, sin poder moverse a ninguna parte, a fin de poder remover en su mente las visiones que guarda su espíritu.

Sin embargo, no es posible, pasar de largo, sin decir dos palabras, acerca de los escritores que nos han hablado del norte. Pocos son, pero hay en ellos, méritos que no podemos desconocer y los citaremos aun cuando no se dedicaron al cuento, tema que nos mueve a escribir estas líneas. Para ello comenzaremos por citar a José Joaquín Vallejos, (Jotabeche) que aparece en la primera mitad del siglo pasado, quien logra animar algunos cuadros de costumbres, y de crítica al ambiente de la época, a los cuales consigue infundirles ciertas características propias del cuento y que son como el primer vajido o anunciamiento de este género. De esa misma época, mencionaremos también a Manuel Concha que en sus «Tradiciones serenenses», nos da interesantes notas de color y de ambiente de esas tierras y lo mismo a Adolfo Valderrama en sus «Cartas» cada una de las cuales contiene un cuento, no del todo logrado, pero que casi alcanza esta forma en *Taita Pedro», en donde hay pinceladas que están muy bien, del campo de La Serena. 
Le sigue después, Honorio Henríquez, poeta de no escasos méritos, con su novela «Por la gloria de San Ambrosio» premiada en la Argentina, en un importante concurso de novelas americanas; y finalmente Víctor Domingo Silva, que en su «Pampa Trágica» de relatos muy interesantes, no alcanza sin embargo, a captar ni ahondar en ese sentido trágico de ella, y Guillermo Koenenkampf que ha publicado dos cuentos muy hermosos, en las revistas de Santiago, titulados "Cruces en el Norte» y «La Pampa» en los cuales demuestra conocer el ambiente y las costumbres de la región del salitre.

No es cosa tan fácil determinar la aparición del cuento chileno, que hasta poco antes del novecientos, no consigue destacarse, perdido entre la novela y el folletín, con caracteres bien definidos. Es con la generación que comienza a producir ese año, cuando entra en un período de franco florecimiento. Son los escritores de ese tiempo los padres de este género en Chile, al cual dan el sentido y la proporción, sin llegar naturalmente a la perfección de ellos, que se advierte en las creaciones de Maupassant y Zola. En este aspecto de la obra literaria nacional, son pilares inamovibles los nombres de Federico Gana, Joaquín Díaz Garcés, Baldomero Lillo, Augusto Thompson, Guillermo Labarca, Januario Espinosa, Fernando Santiván, Eduardo Barrios, Rafael Maluenda y Mariano Latorre, pléyade brillante de hombres de rico y poderoso temperamento de escritores, cuya vocación afronta gallardamente todas las dificultades e indiferencias del medio. Los tres primeros, ya desaparecidos del escenario, mueren cultivando su arte. Los demás perseveran en él, con el entusiasmo y la fe de los primeros días, a excepción de Guillermo Labarca, a quien coge la política en sus re- 
des tentadoras, en donde también demuestra su claro talento, y de Rafael Maluenda al cual absorbe el periodismo, pero que según nuestras noticias tiene numerosa obra sin publicar.

¿Por qué se singulariza la obra de estos escritores? ¿Cuáles son las características principales de sus concreciones artísticas? Guiados por esa luz interna, que es el instinto, cuando todavía no han llegado a la madurez, comprenden bien el papel que les toca desempeñar. No eligen por supuesto los temas imaginativos, ni los complicados problemas psicológicos, ni las absurdas complejidades sexuales. Nada de esto los tienta, y comienza por donde debían. Afirmando los pies sobre la tierra nativa y extendiendo la mirada hacia el paisaje, para en seguida buscar en el elemento humano, el sentido autóctono de la raza, con sus modalidades y sus características, que en un país como el nuestro sin amor a la tradición, la civilización hará muy pronto desaparecer.

Uno de los primeros a quien interesa el campo, es Federico Gana, y lo mira de arriba hacia abajo. Es el señor con alma de artista, que se detiene a contemplar el campo y sus habitantes, cuando sale en su caballo de fina sangre y acompañado de sus perros, a recorrer los potreros, donde hay alamedas muy derechitas, entre los cuales cantan los jilgueros y los zorzales. En su libro «Días de Campo» hay descripciones de tipos un tanto estilizadas, que hablan y se mueven, sin que se advierta en ellos gran diferencia con la gente de la ciudad. Sin embargo, el da la primera visión del campo y despierta el interés por él, en sus cuentos, entre los cuales citaremos, «La Maiga y «La señora». Casi por el mismo tiempo comienza Joaquín Díaz Garcés que, hurga en el pasado con gran acierto. Prueba de ello son *La Trinitarias», «Tarpeyanca», *A la sombra de la Horca». También algunos cuentos campesinos entre los cuales recordamos «Juan Neira , una especie de 
arquetipo, en el cual se concentra todo el valor y la lealtad que el autor atribuye al huaso.

Baldomero Lillo, en su fuerte y hermoso libro a SubTerra" nos hace conocer la vida de los mineros del carbón. Con pinceladas maestras, describe la tremenda tragedia del obrero que se hunde en el pique lóbrego en donde su vida está expuesta a cada instante. Inolvidable por ese soplo de fatalismo, y su sombrío relieve nos parece «El Chiflón del Diablo». En D'Halmar, se insinúa muy pronto, una tendencia decidida a salirse de la realidad, no sin antes haberla conocida. Vivo testimonio de este aserto es el contenido de sa lámpara en el molino». Esta tendencia después se ahonda en él, ayudada por su poderosa fantasía y por sus errancias a través del mundo, lo que imprime un sello inconfundible a su obra.

Guillermo Labarca, triunfa por ese tiempo, en un concurso de Zig-Zag, que alcanza gran resonancia, con un cuento criollo «El Acriminado». De esta misma tendencia son los relatos de su libro « $\mathrm{Al}$ amor de la tierra". Este escritor comienza ya a darle importancia al paisaje, y capta con ojo certero muchos detalles y costumbres, de la vida campesina. Maluenda, puede decirse que es el novelista de la clase média. Sabe como pocos, comunicar livianura, simpatía y colorido a sus narraciones. Incorpora también a la literatura las leyendas de los bandidos chilenos, dando mucho carácter e interés a la figura de Ciriaco Contreras. En otros aspectos de su obra, mencionaremos \&La Pachacha» ingeniosa y aguda sátira al ambiente de la sociedad provinciana, y sus "Escenas de la vida campesina». Junto a él está Januario Espinosa, quien en un estilo limpio y sabroso enhebra sus relatos alrededor de las vidas humildes. Empleado durante muchos años en el telégrafo, se demuestra como un observador certero de la medianía que caracteriza al ambiente que lo rodea. Ha cultivado más la novela ( Cecilia» fué todo un éxito), 
que el cuento, el cual, sin embargo, trata con mucho acierto. Su libro «Un viaje con el diablo» es un bello testimonio para apoyar nuestra afirmación.

Eduardo Barrios, ha dedicado su preferencia a la novela en la cual ha obtenido sonados éxitos. Sus libros han sido editados en España, en donde es ventajosamente conocido entre el elemento intelectual. Escribe en una prosa atildada, pulida, brillante, y demuestra agudeza para descubrir algunos aspectos psicológicos de sus personajes. Tiene un libro de cuentos de juventud, titulado «Del natural». Los más logrados forman parte de su volumen «Memorias de un pobre diablo».

Santiván trae al cuento chileno, una delicada fibra romántica. Su prosa es cálida y de gran riqueza emocional. En sus cuentos campesinos palpita el alma popular, con auténtica expresión. Allí está el roto fatalista, sombrío en sus trágicas encrucijadas pasionales, que no alcanzan esa vibración angustiada que conmueve internamente al hombre civilizado, sino que estallan con la desatada violencia, de las fuerzas ciegas, sin ningún control. En * Era tan lindo» y \& Pellines sobre el río» son expresiva muestra de la ternura y poesía que guarda el espíritu del autor de \& La Hechizada».

Y llegamos a Mariano Latorre, que es a nuestro juicio, el más decidido explorador de nuestro territorio, que le sirve de escenario en sus más variados aspectos para ubicar y ambientar los motivos y personajes que se agitan dentro de su imaginación. Con un inmenso cariño por su tierra que conoce como ninguno de nuestros escritores extrae de cada rincón, lo que su espíritu descubre, como cosa propia de allí. Creemos que con él nace, y adquiere su verdadero sentido autóctono el cuento criollo. Una buena parte de sus años de niño los vive en el campo y también junto al mar. Esas visiones inolvidables de su infancia se hacen carne palpitante de recuerdos en su alma de artista, que se avi- 
van $y$ refrescan con sus continuados viajes, al campo en donde pasa por lo menos tres meses en el año. $Y$ es así, cómo logra trasparentar con vigor inusitado, la grandeza épica de la cordillera, con sus claro obscuro de sol sobre las cumbres, y de abismos donde tirita el vértigo; de cóndores audaces en sus vuelos magníficos, junto al azul del cielo, cuando escrutan con ojos penetrantes, los senderos que arañan los farellones, en donde a veces se pierden los baqueanos entre el laberinto de encrucijadas, trágicas de soledad y de misterio. «La epopeya de Moñi», «La viña de Dios», «Cóndor Viejo», son aciertos estupendos en este aspecto de la obra de Latorre. Así, cuando describe la selva con sus aromas intensos, sus árboles gigantes, y sus pájaros ocultos en la umbría espesa de follaje adquieren en su pluma la poética frescura de un poema, tal en: *Un filón de rico raulí». Otras veces palpita en sus relatos, un aliento cálido y perfumado, que da la impresión de ir cruzando por entre quebradas florecidas de ulmos y copihueras, o por entre lomajes donde ondulan los trigos maduros, como en «Marimán o el cazador de hombres». En sus cuentos marinos hay páginas que hubiera firmado Conrad: «Cárcamo», «El pontón N. ${ }^{\circ} 5$ y $\propto \mathrm{El}$ finado Valdés». Y el alma desolada, agria y escueta de las tierras pobres está en «Zurzulita» y muchos de sus cuentos.

Latorre es el primero que trata con acierto, el lenguaje popular de nuestros huasos, sin valerse simplemente de deformaciones de las palabras, sino usando esos giros que no son estrafalarios como se cree, sino la mezcla de palabras que usaron los conquistadores, y del mapuche, que tanto sabor de chilenidad prestan al relato, y le dan el relieve propio en donde está el alma nativa, con un acento humano inconfundible. Esto ha sido muy criticado en Chile, alegando que restringe el valor de la obra artística, o que es tarea para fonógrafos. Sin embargo, las grandes obras de la lite- 
ratura americana, lo ostentan orgullosas y trasponen fronteras: "Don Segundo Sombra", "Los de Abajo", "La Vorágine», «Doña Bárbara». Lo usa Pérez Galdós, en sus *Episodios nacionales», Blasco Ibánez en sus obras más logradas; Palacio Valdés en la "Hermana San Sulpicios y tantos otros libros que triunfan ampliamente y que hasta son premiadas por la academia de la lengua, como «Tigre Juan». El reparo como se ve es injusto. Lo que se debe criticar no es eso, sino la deformación absurda y tonta de las palabras. Porque a nuestro juicio, resulta ridículo hacer hablar a nuestros campesinos, como académicos, o personas que tienen un cabal conocimiento del lenguaje.

Entre tanto es curioso anotar, que en esta generación de escritores de que hemos hablado tan brevemente, no aparece ninguna mujer. Es mucho después, cuando se destaca el nombre de Amanda Labarca, que en su volumen «La lámpara maravillosa» tiene cuentos muy hermosos, entre los cuales recordamos "Los cuatro", que denuncia un temperamento a la vez fino $y$ vigoroso para enfocar la realidad.

No terminaremos estas breves anotaciones, sin dedicar algunas palabras, a la generación de escritores contemporáneos, los cuales son ya una realidad lisonjera, y quien sabe si pudiéramos decir sin pecar de exagerados una magnífica promesa para el cuento chileno. Tales son los nombres de Acevedo Hernández, hombre de gran talento, en cuya obra se advierte un deseo ardiente y fervoroso, por exaltar las cualidades del pueblo. Carlos Acuña, que con conocimiento perfecto del ambiente, tiene cuadros bellísimos, saturados de chilenidad y olorosos a campo. Manuel Rojas, con sus campesinos y rotos aventureros, que traza con todo el relieve de que es capaz su fuerte personalidad de escritor. 
Lautaro Yankas, temperamento un poco frío que en un estilo muy peculiar, tiene excelentes cuentos criollos. Marta Brunet, en la cual hay un marcado acento trágico, tiene aciertos magníficos en sus asuntos campesinos, tema que es lástima haya dejado, pues lo trataba muy bien. Armando Arriaza (Hermes Nahuel), obtiene el premio Blasco Ibáñez, con su novela "Puñado de viento sur», y es autor, además, de un tomo de cuentos campesinos titulado «Esclavos». González Vera, cuya prosa contenida y un tanto fría, acusa no obstante una personalidad curiosa y original. Es una especie de Flaubert criollo, que exige demasiado a su estilo. Ha obtenido resonantes éxitos de crítica con sus libros «Vidas Mínimas» y *Alhué» el primero, pintura muy acertada del ambiente y de los tipos del conventillo santiaguino, y el segundo cuadros muy bellos, o estampas de una aldea, como él las llama. Gmo. Koenenkampf, demuestra especiales condiciones para el cuento, en sus narraciones que sitúa en la provincia de Aconcagua, su tierra nativa. Su libro de próxima publicación será, estamos seguros, una revelación de su capacidad para cultivar este género. Juan Marín tiene también una colección de interesantes relatos por publicar, algunos de los cuales ya han visto la luz en los diarios de Santiago.

También han hecho obra muy meritoria e interesante Germán Luco con sus narraciones costumbristas de ambiente sureño y Oscar Lanas con sus cuentos marinos, que es autor de la "Canción del Navinato".

Ernesto Montenegro y Luis Roberto Boza, publican tardíamente sus cuentos en un volumen. El primero con su «Tío Ventura» que es toda una creación, obtiene un merecido triunfo de crítica y de librería. "Los Aparecidos» es el título del libro del segundo, el cual creemos que fué recibido injustamente y casi con crueldad por la crítica. Boza es autor de un cuento muy original titulado «El Puma". 
Sin imitarlo, pero siguiendo las huellas de D'Halmar, están, Salvador Reyes y Luis Enrique Délano. Salvador Reyes con grandes dotes de imaginación, en una prosa ágil, liviana, trasparente, no ubica sus relatos en parte determinada. Ha publicado recién un tomo de cuentos: «Lo que el tiempo deja», el cual ha merecido un elogioso juicio de Francis de Miomandre. Los relatos de Luis Enrique Délano, están saturados de poesía y ensueño, llenos de dulces y lejanas vibraciones. Alrededor de su primer libro "La Niña de la prisión», se formó una interesante polémica de prensa, acerca de la literatura a base de pura imaginación. Forma parte de ese libro su cuento «Al punto Mayor» sobre el cual se han hecho los mejores comentarios.

Al terminar esta sencilla reseña sobre el cuento en Chile, creemos necesario, citar los nombres de otros escritores que también lo han cultivado sin dedicarle su preferencia. Entre ellos mencionaremos a don Luis Orrego Luco, con su libro "La vida que pasa". Joaquín Edwards, con sus "Cuentos de todos colores» y "Los Lunes» de "La Nación». Además los novelistas Alberto Romero, Sady Zañartu y el poeta Augusto Iglesias, quienes los han publicado en diarios y revistas, sin reunirlos en un volumen. 